\title{
Serological evidence of Legionella species infection in acute exacerbation of COPD
}

\section{To the Editor:}

We are concerned about the alleged aetiological role of Legionella spp. in acute exacerbations of chronic obstructive pulmonary disease (AECOPD), as has been recently suggested by both LIEBERMAN et al. [1] in their study published in the European Respiratory Journal, and EwIG [2] in an editorial in the same issue [2]. To the best of our knowledge, the distinctive results of the study by LIEBERMAN et al. [1] have not been reported in any other aetiological survey of AECOPD. A recent, in-depth review of bacterial infection in chronic obstructive pulmonary disease, by a worldwide expert on this subject, does not even mention any role for Legionella spp. in AECOPD [3]. Although attachment to bronchial cells is the first step of Legionella spp. infection, it is well known that the primary pathogenic process takes place at the macrophage cell level. There are no consistent data that might favour a theoretical isolated infectious bronchitis without any pneumonic involvement [4]. In fact, Legionella spp. isolation remains the gold standard for diagnosing any form of Legionella infection [5]. An exhaustive review of AECOPD studies that have focused on the search of an aetiological agent by means of invasive procedures, such as bronchoscopic techniques, shows that Legionella spp. have never been identified until now. Moreover, the provided clinical data do not seem to correspond with the clinical syndrome of Pontiac fever.

Doubts about the validity of serological testing for a reliable diagnosis of Legionella infection can definitely be seen if the accumulated experience on these techniques during the last $25 \mathrm{yrs}$ is reviewed. There are two well-known drawbacks of serology: low sensitivity, even for Legionella pneumophila serogroup $1(<70 \%)$ [5], and a serious concern about specifity [6]. Specificity $(\sim 96-99 \%)$ has only been acceptably established for $L$. pneumophila serogroup 1. Crossreactivity between $L$. pneumophila serogroup 1 and other serogroups and species has been consistently reported in the literature [7].

The risk of false-positive results should then not be neglected since the use of a completely nonspecific diagnostic method in a low prevalent disease, such as legionellosis, will, from a statistical point of view, undoubtedly increase the likelihood of false-positive reactions. This risk must be even higher when considering serology for non-L. pneumophila serogroup 1 infections and especially Legionella spp. other than $L$. pneumophila [8]. In fact, as EwIG [2] points out, if only L. pneumophila serogroup 1 had been evaluated, the incidence of alleged Legionella infection would have decreased to $4 \%$. The concept of unreliable specificity of immunofluorescent antibody (IFA) for diagnosing clinically relevant infections by Legionella is also supported by some studies. ANDERSEN et al. [9] found a clinically silent four-fold indirect IFA seroconversion in their prospective study on annual (3-5 yrs) serum specimens among 52 children, more than 20 -yrs ago. More recently, a four-fold IFA asymptomatic seroconversion has also occasionally been observed in high-risk populations such as adult renal transplantation patients [10]. In a study by DowLING et al. [11], $7 \%$ of their 89 receptors seroconverted during the 6 months after transplantation, without any clinical evidence of pneumonia. In a recent cohort study, after an outbreak of travel-associated Legionnaires disease and Pontiac fever, 3-6\% of patients who were not ill showed immunoglobulin (Ig)G seroconversion or IgM seropositivity, respectively [12].

A variety of possible serological cross-reactions have been reported in the literature. Among them, some Gram-negative bacteria and anaerobic microorganisms, including Pseudomonas, Proteus, Bordetella and Bacteroides fragilis, may sometimes be incriminated in AECOPD [6]. Moreover, cross-reactions have also been reported with certain microorganisms that may be endemic or cause epidemic outbreaks in determined geographical areas, such as Ricketssia conorii, the agent of Mediterranean fever, $R$. typhii, the agent of murine typhus, Coxiella burnetii, and Campylobacter spp. [13-16]. Synchronous serological studies would perhaps have been appropriate. We could also speculate on a possible cross-reactivity of Legionella spp. with other less studied common human pathogens that share some similarities. For example, serological cross-reaction between Capnocytophaga spp. and Legionella spp. has been reported [17] and these periodontal bacteria seem to be frequently identified by polymerase chain reaction (PCR) assay in apparently periodontally healthy subjects [18]. In addition, Helicobacter pylori has shown cross-reactivity with L. micdadei [19]. This finding could be of interest if further studies confirm that preliminary report, since $H$. pylori seropositivity has been reported to be common both in chronic bronchitis [20] and bronchiectasis [21]. In fact, chronic bronchitis has been identified as a predictive factor of seropositivity for $\mathrm{IgG}$ antibodies to H. pylori [22].

In any case, if we accept that seroconversion means real infection, it is worth remembering that, in their outbreak case-control study, BosHuizen et al. [23] recently observed that control seroconvertors did not show any statistically significant clinical difference when compared to nonseroconverters. Their results would suggest then that Legionella infection could 
theoretically produce either pneumonia or just asymptomatic infection.

\section{J. Roig*, X. Soler", C. Domingo ", G. de Celis ${ }^{+}$}

*Pulmonary Division and ${ }^{+}$Dept of Internal Medicine, Hospital Nostra Senyora de Meritxell, Escaldes, Principality of Andorra. "Servei de Pneumologia, Hospital Germans Trias I Pujol, Badalona and "Servei de Pneumologia, Corporació Hospitalària Parc Taulí, Sabadell, Barcelona, Spain.

\section{References}

1. Lieberman D, Lieberman D, Shmarkov O, et al. Serological evidence of Legionella species infection in acute exacerbations of COPD. Eur Respir $J$ 2002; 19: 392-397.

2. Ewig S. Legionella spp. in acute exacerbations of chronic obstructive pulmonary disease: what is the evidence? Eur Respir J 2002; 19: 387-389.

3. Sethi S, Murphy TF. Bacterial infection in chronic obstructive pulmonary disease in 2000: a State-of-theArt review. Clin Microbiol Rev 2001; 14: 336-363.

4. Andersen P. Pathogenesis of lower respiratory tract infections due to Chlamydia, Mycoplasma, Legionella and viruses. Thorax 1998; 53: 302-307.

5. Roig J, Rello J, Yu VL. Legionnaires' disease: a guide to diagnosis and therapy. J Respir Dis 2002; 23: 229 234.

6. Maiwald M, Helbig JH, Lück PC. Laboratory methods for the diagnosis of Legionella infections. $J$ Microbiol Methods 1998; 33: 59-79.

7. Wilkinson HW, Reingold AL, Brake BJ, McGiboney DL, Gorman GW, Broome CV. Reactivity of serum from patients with suspected legionellosis against 29 antigens of legionellaceae and Legionella-like organisms by indirect immunofluorescence assay. $J$ Infect Dis 1983; 147: 23-31.

8. Bornstein N, Janin N, Bourguignon G, Surgot M, Fleurette J. Prevalence of anti-Legionella antibodies in a healthy population and in patients with tuberculosis or pneumonia. Pathol Biol (Paris) 1987; 35: 353 356.

9. Andersen RD, Lauer BA, Fraser DW, Hayes PS, McIntosh K. Infections with Legionella pneumophila in children. J Infect Dis 1981; 143: 386-390.

10. Renoult E, Kessler M, Jonon B, Schmit JL. Significance of seroconversion against Legionella after renal transplantation: report of five cases. Clin Nephrol 1990; 33: 209.

11. Dowling JN, Pasculle AW, Frola FN, Zaphyr MK, Yee RB. Infections caused by Legionella micdadei and Legionella pneumophila among renal transplants recipients. J Infect Dis 1984; 149: 703-713.

12. Benin AL, Benson RF, Arnold KE, et al. An outbreak of travel-associated Legionnaires disease and Pontiac Fever: the need for enhanced surveillance of travelassociated legionellosis in the United States. J Infect Dis 2002; 185: 237-243.

13. Raoult D, Dasch GA. Immunoblot cross-reactions among Rickettsia, Proteus spp. and Legionella spp. in patients with Mediterranean spotted fever. FEMS Immunol Med Microbiol 1995; 11: 13-18.
14. Bernabeu-Wittel $\mathrm{M}$, Pachón $\mathrm{J}$, Alarcón A, et al. Murine typhus as a common cause of fever of intermediate duration. A 17-year study in the south of Spain. Arch Intern Med 1999; 159: 872-876.

15. Musso D, Raoult D. Serological cross-reactions between Coxiella burnetii and Legionella micdadei. Clin Diagn Lab Immunol 1997; 4: 208-212.

16. Boswell TC, Marshall LE, Kudesia G. False-positive Legionella titres in routine clinical serology testing detected by absorption with Campylobacter: implications for the serological diagnosis of legionnaires' disease. J Infect 1996; 32: 23-26.

17. Chen S, Hicks L, Yuen M, Mitchell D, Gilbert GL. Serological cross-reaction between Legionella spp. and Capnocytophaga ochracea by using latex agglutination test. J Clin Microbiol 1994; 32: 3054-3055.

18. Kimura S, Ooshima T, Takiguchi M, et al. Periodontopathic bacterial infection in childhood. $J$ Periodontol 2002; 73: 20-26.

19. Andersen LP, Espersen F. Immunoglobulin G antibodies to Helicobacter pylori in patients with dyspeptic symptoms investigated by the western immunoblot technique. J Clin Microbiol 1992; 30: 1743-1751.

20. Caselli M, Zaffoni E, Ruina M, et al. Helicobacter pylori and chronic bronchitis. Scand J Gastroenterol 1999; 34: 828-830.

21. Tsang KW, Lam SK, Lam WK, et al. High seroprevalence of Helicobacter pylori in active bronchiectasis. Am J Respir Crit Care Med 1998; 158: 1047-1051.

22. Rosenstock SJ, Jorgesen T, Andersen LP, Bonnevie O. Association of Helicobacter pylori infection with lifestyle, chronic disease, body-indices, and age at menarche in Danish adults. Scand J Public Health 2000; 28: 32-40.

23. Boshuizen HC, Neppelenbroek SE, van Vliet $\mathrm{H}$, et al. Subclinical Legionella infection in workers near the source of a large outbreak of Legionnaires disease. J Infect Dis 2001; 184: 515-518.

\section{From the author:}

There is no agreement on the answer to the question concerning the preferred method for the diagnostic aetiology of respiratory tract infections in general and of Legionella spp. in particular.

The opinion expressed in the letter by J. Roig and colleagues presents one side of the spectrum of opinions on this issue. Their explicit opinion that Legionella isolation remains the gold standard for diagnosing any form of Legionella infection is a minority position, so it is no coincidence that the reference quoted by them in support of this position is their own. This approach assumes an optimal and, in our opinion, unrealistic assumption that in all cases of Legionella infection it is feasible to isolate the pathogen. This approach completely ignores the difficulty involved in obtaining appropriate material for the isolation of the pathogen in some of the patients, as well as the technical complexity of the isolation. Defining this problematic laboratory test as a gold standard would turn the 